Review

\title{
Electrical Heating for Heavy Oil: Past, Current, and Future Prospect
}

\author{
M.Y. Hasibuan ${ }^{1 *}$, S. Regina ${ }^{1}$, R. Wahyu ${ }^{1}$, D. Situmorang ${ }^{1}$, F. Azmi ${ }^{1}$, R. Syahputra ${ }^{1}$, L.P.Y. \\ Batubara 1, F. Prabowo ${ }^{1}$, A. Setiawan' ${ }^{1}$, M.F. Alfin ${ }^{1}$, M.K. Afdhol ${ }^{1}$, T. Erfando ${ }^{1}$ \\ 1 Department of Petroleum Engineering, Universitas Islam Riau, Jalan Kaharuddin Nasution No. 113, \\ Pekanbaru 28284, Indonesia; afdhol@eng.uir.ac.id (M.K.A.); tomierfando@eng.uir.ac.id (T.E.) \\ * Correspondence: mhdyudatamahsb@student.uir.ac.id; Tel.: +62-812-2723-6659
}

\begin{abstract}
This paper presents a review of the electrical heating method for heavy oil recovery based on past, current, and future prospects of electrical heating. Heavy oil is one of the potential crude oil used as a link to reduce the crisis of light oil used today. The obstacle of heavy oil is a high viscosity and density in which thermal injection is a method for heavy oil recovery, but it results in economic and environmental issues. Electrical heating is one of the thermal methods by transferring heat into the reservoir. The basic process of electrical heating is to increase the mobility of the oil. Because the temperature rises, it can reduce oil viscosity and makes it easier for heavy oil to flow. The past and current developments have been carried out to fill up the gap of electrical heating projects. The future prospects must meet energy efficiency, and the excessive heat will damage formation that must be tackled in the future prospect. the works adopt several electrical heating projects and applications in the world where the works give a brief future prospect of electrical heating.
\end{abstract}

Keywords: electrical heating; heavy oil; visocsity; energy efficiency

\section{Introduction}

Crude oil is one of the main energy sources that are the most widely used today. Oil consumption is increasing every year, but oil production has been declining. Hence, the light oil which easy to be produced has been already extracted [1]-[3]. Heavy oil reserve is $70 \%$ of total world oil reserves [4], but the issue is faced with heavy oil reserve is a high viscosity and density due to higher asphalt and sulfur components than conventional oil [5]. Therefore, it becomes a challenge to produce crude oil from the reservoir both technically or economically [6]. The obstacles of heavy oil production include the following :

1. Difficult to be recovered then it more expensive

2. The massive heat is required to be more mobile

3. Contains impurities that must be removed such as sulfur, heavy metal waxes, and residue [7].

Most of the heavy oil comes from conventional oil that is deposited in deep formations, but it migrates to areas that are affected by bacteria and weathering [8]. Therefore, a conventional method can't be applied in low API $(<20)$ reservoir [9], heavy oil/bitumen can be produced using both thermal and steam injection that can help to reduce the viscosity of heavy oil [10]. 
Table 1 crude oil classifications

\begin{tabular}{|l|c|c|c|}
\hline \multicolumn{1}{|c|}{ Material } & Gravity, ${ }^{\circ} \mathrm{API}$ & Density, $\mathrm{kg} / \mathrm{m}^{3}$ & Viscosity, mPa.s \\
\hline Bitumen & $<10$ & $>1000$ & $>10^{5}$ \\
\hline Extra heavy oil & $<10$ & $>1000$ & $<10^{5}$ \\
\hline Heavy oil & $10-19$ & $900-1000$ & $10^{2}-10^{5}$ \\
\hline Medium crude oil & $19-34$ & $855-900$ & - \\
\hline Light crude oil & $34-42$ & 915 & - \\
\hline
\end{tabular}

There are two methods of reservoir heating which most of them are electrical heating and thermal injection. Thermal or steam injection is a method for heavy oil recovery that can be widely applied. However, the thermal method has some disadvantages related to economic and environmental issues. This method also couldn't be applied to the reservoir which has high and clay contents, deep formations, and heterogeneous reservoirs [11]. Electrical heating is one of the thermal methods by transferring heat into the reservoir. Because the temperature rises, it can reduce oil viscosity and makes it easier for solid materials to flow. These effects can help in sweeping oil out of the formation when there are media that can help to drive oil such as gravity drainage because the basic process of electrical heating is to increase the mobility of the oil by reducing oil's viscosity, and then the oil can flow easily to the production well [2].

In the electrical heating method utilizing a heat transfer system uses an electrode where the electrode will flow an electric current. The electric current will leave the electricity generator and flows downwards to the electrode that directly has electrical contact with reservoir formations. From the electrode, an electric current flows through the reservoir and flows back to the surface or power supply. The amount of required electric current depends on the rate of production because, when the hot water is producing, the colder fluid will be flowing from the reservoir to the well. If there is much energy used, it will give uncontrolled temperature and damages formation [12].

Critical research works have given a high impact on the application of electrical heating to have large oil cumulative for the enhanced oil recovery method. Currently, there are numerous active electrical heating for many EOR projects. the works adopt several electrical heating projects and applications in the world, where this research can be useful as guidelines for determining the electrical heating application method to be implemented in the future.

\section{Mechanisme of Electrical Heating}

The mechanism of electrical heating generally is divided into two types, electrical heating for vertical well and horizontal well using a thermal process either to heat steam chamber or direct heating into the near-wellbore of vertical well and horizontal well [13]-[16]. Electrical heating is also using the SAGD process heating the formation by gravity drainage [17], [18]. The amount of power is determined by the production rate and operational requirements, depending on each well and formation. As flow rate increases, more electricity is required to compensate. The process of the electrical heating system occurs while oil is produced, there is no fluid required for injecting the reservoir. Therefore, the formation damage is none. But the electrical heating is used for heating steam chamber [19], an electrical heating path is affected by brine and electrical energy is dissipated due to heat. As water saturation decreases or the majority of the water has been forming steam because of heated by electric current [20]. 


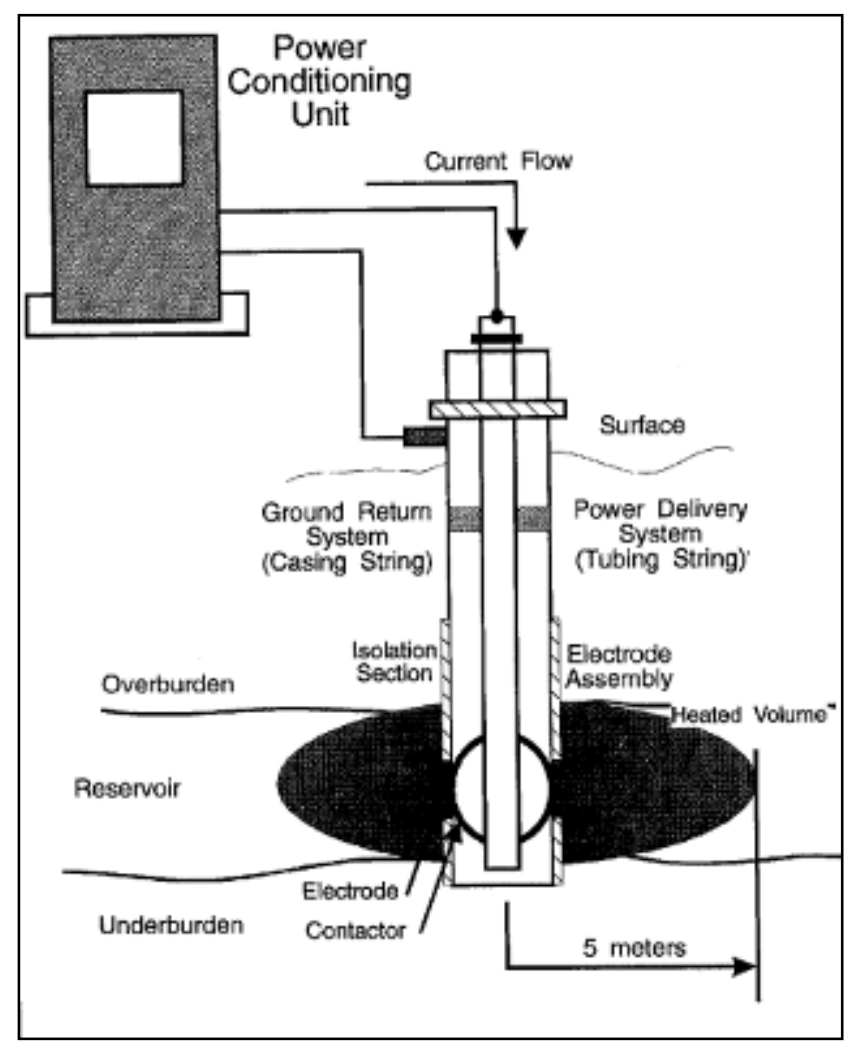

Figure 1. Electrical heating single wellbore configuration (oil production equipment not shown)

The mode of electrical heating depends on the frequency of the electric current. Polar molecules tend to align and relax with the alternating electric field. The molecular movement may result in significant heating [21]. There are several important components in electric heating applications including; power conditioning unit, power delivery system, electrode assembly, and ground return system. On the delivery system, the main project of electrical heating design is to minimize the electrical losses and to avoid localized heating. Meanwhile, the electrode assembly consists of a bare casing pipe with fiberglass electrical isolation. The objectivity of the electrode assembly is to optimize the effectiveness of heating in the oil reservoir. The current return is the casing string above the fiberglass using isolated electricity joint between the casing and the electrode for a single well system. Current flows from the power conditioning unit and is conducted down the power delivery system to the electrode assembly, then the current flows through the oil formation and returns to the power conditioning unit system. Therefore, oil viscosity can be reduced properly by heating [19]. There are advantages of electrical heating below :

1. No fluids injected

2. Heating while producing at the same time

3. The efficiency of volumetric sweeping is greater than thermal injection because the electric current could flow in the low permeability

4. Able to a reservoir containing clay swelling

5. Reducing heat loss

\section{Conventional Method for Heavy Oil Recovery}

Thermal recovery can help reservoir to be heated to reduce oil viscosity. Thermal EOR is the most popular method for heavy oil which more than $50 \%$ of total EOR projects in the world, which of them is the most common method used for thermal injection is steam injection. According to the screening criteria of steam injection, it is mostly applied in shallow reservoir that has high viscosity called heavy crude oil [22]-[25]. Thermal injection needs to maintain the fluid inejction due to pressure required which fluid is injected continuously into the reservoir that displaces oil and obtains a higher production [8]. 


\subsection{Hot water injection}

Hot water can be injected into strata hydrocarbon which is useful for reducing the viscosity of heavy oil [26], therefore the heavy oil will flow easily and can increase production due to heat transfer that occurs between the hot water fluid and the heavy oil. A project in the middle eastern reservoir with large heavy oil deposits had a viscosity of 500cp where the hot water injection method increases oil recovery by $25 \%$. However, the disadvantage of hot water is that is less efficient due to less heat content compared to the steam injection method [27].

\subsection{Cyclic steam stimulation}

In recent years, the exploitation of heavy oil has adopted method of cyclic steam stimulation (CSS) [28]. Cyclic steam stimulation (CSS) is one of the effective methods for the recovery of crude oil which has high viscosity such as bitumen, heavy oil, etc. Cyclic steam stimulation is often the preferred method for production in heavy oil reservoirs that can contain high-pressure steam without fracturing the overburden. The application of CSS is usually at a depth formation, more than 1000 feet. It depends on the type and structure of the formations [29]. CSS has several disadvantages, one of which is a relatively low recovery factor, which is around (26-35\%). The highest recovery factor of the CSS increases the recovery factor of around $40 \%$, but it is less effective than other thermal injection methods such as SAGD (60-70\%) and steam injection (50-60\%). Besides it, the disadvantages mentioned above, CSS has the advantage of being more energy efficient with lower emission intensities than other thermal injection methods. For example, the results of the research on the application of CSS in the Melibur field, Padang-Indonesia which a reservoir contains heavy oil with viscocity 9-12 Cp and 22-26 API gravity oil, showed that CSS is an effective recovery method used in the extra-heavy oil reservoir. Heavy oil that has high viscosity is a challenge to produce. Cyclic steam stimulation is the preferred method for removing oil because it is most likely suitable for this field. And the results, with CSS injections a few months to produce results that are quite maximum with a total of recovery factor of $40 \%$ [30].

\subsection{Thermal injection}

Thermal recovery, or more specifically steam injection, is the most successful recovery technique used today to be applied to improve oil recovery [31]. The thermal injection can rapidly reduce viscosity, improving producibility substantially, and shifts rock wettability to conditions more favorable for oil recovery. Thermal recovery is commonly applied to heavy oil wells, but not heavy oil can be applied for thermal injection, thermal injection can also be applied to lighter oil and more heterogeneous formations [32] . The thermal injection is quite successful because it can increase oil recovery substantially. The heat transfer can sweep the side of the reservoir which never did oil have contact with the injection such as steam injection. Therefore, thermal recovery has replaced resources into reserves and is projected to play a greater role in the future of heavy oil recovery, which one of them is electrical heating.

\subsection{Steam Assited Gravity Drainage}

Steam Assisted Gravity Drainage (SAGD) is one of the thermal recovery techniques used for the recovery of heavy oil or bitumen [33], [34]. Steam Assisted Gravity Drainage (SAGD) has become a technology that has been applied to recover crude oil with high viscosity and has realized large-scale commercial applications through steam injection, cold oil is heated while the steam is condensed into the hot water [35]. The hot fluid is resulted by gravity drainage. There are two methods of placing wells for SAGD method that is a vertical well and a combination of horizontal wells [36], and another is the dual-horizontal well pattern which is the most common way in the SAGD project [37]. The uniqueness of the Steam Assisted Gravity Drainage (SAGD) recovery process lies in the salient role of moving boundary boundaries and counter-current flows [14], [38]. The disadvantage of the SAGD method is the high cost for installation and steam [39]-[41]. 


\subsection{In-Situ Combustion}

The study of in-situ combustion has been developed in many years due to increasing heavy oil recovery. Either forward or reverse combustion requires the handling of large volumes of air at high pressures [42]. In-Situ Combustion is one of thermal enhanced oil recovery processes injecting oxidizing gas (air or oxygen-enriched air) into the reservoir to generate heat by burning a portion of the oil thereby reducing the viscosity of oil and can flow to the well easily, It involves ignition in the well and injection of air to sustain flame front. In this process a small portion of oil will ignite, producing $\mathrm{CO} 2$, water vapor, and heat. The objectivity of thermal injection is to increase oil mobility by the heating method [43]. The heat energy driven by in-situ is injecting gas containing oxygen into the reservoir to combustion method [44]. Then the oil is pushed towards the production well using a gas drive combination (from the combustion gases) and steam and water drive. The difference between in-situ combustion method than others is that heat is generated at the surface and then injected into the reservoir [45].

In-Situ Combustion has long been used as an improved oil recovery method. For heavy oils, many field observations show an increase of API $2^{\circ}$ to $6^{\circ}$ for heavy oil that experience combustion [46]. In-situ combustion was once applied to the northern part of the Cambay Basin located in Mehsana, Gujarat (India), which has several heavy oil fields with reserves of around 140 MMT OOIP. Oil viscosity ranges from 50 to $450 \mathrm{cp}$. High mobility contrast between viscous oil and water makes the primary recovery low. The artificial lift method has been applied but it makes water production higher than oil. Therefore, in-situ combustion techniques are used to replace of artificial lift method. The application of in situ combustion in the Mehsana field was successfully implemented. Projects that began in 1991 can increase oil recovery factors from $6-12 \%$ to $39-45 \%$.

\section{Past and Current of Electrical Heating}

Heavy oil is one of the potential crude oil used as a link to reduce the crisis of light oil during the transition from conventional hydrocarbon fuels used today to unconventional hydrocarbon sources. Currently, heavy oil is generally exploited using the steam injection method. This method is quite effective but is not efficient to use because steam injection requires large energy consumption and produces substantial greenhouse gas emissions [47]. Electrical heating is a method of EOR called Electrical-enhanced oil recovery (EEOR) which can be an alternative method used than the conventional method of EOR. There are three fundamental heat transfers of the electrical heating method into the formation (heat conduction, heat convection, and radiation heat transfer) [48]. Heat conduction will transfer heat based on vibrations for each molecule contact. Meanwhile, heat convection is heat transferred from the transfer of gas or liquid with the heat contained in the vicinity, and radiation heat transfer is heat energy transferred through electromagnetic waves. Electrical heating requires electricity sources, but this method can be applied for every situation and can be efficiently transferring heat for the entire reservoir with a big volume that reservoir depth can be neglected [49], [50]. The aim of EEOR is to increase mobility by reducing the viscosity that can flow easily to the production well because electrical energy in the reservoir can raise the temperature and creates vibrations of on hydrocarbon molecules [2], [51].

\subsection{Hybrid Process}

The electrical heating project has been developed in many years designed to replace or supplant another energy process such as steam-assisted gravity drainage [52]. SAGD Process results in GHG Emission where the current limit is 100 million tones/year from oil sand operations and is around $\$ 30 /$ tonne carbon price.

\subsection{Gas and Electrical Heating Assited Gravity Drainage}

This study was represented by Zhong et.al [53] which proposed the mechanism of Gas and electrical heating gravity drainage (GEHGD) for resistance heating in both of vertical and horizontal well. In this study, the injection well was placed on the upper position or higher than lower horizontal well. A gas such as N2, CO2, flue gas, and natural gas was injected which the experimental study has shown a two-fold increase that oil rate increased by six-fold for an $1861 \mathrm{cp}$ [53]. 


\subsection{Electromagnetic Heating Assited Gravity Drainage}

This method was tested in a sandbox, an induction loop embedded in the sandstone layer. The field projects had been planned since 2012, but never did it carry out [54], [55].

\subsection{Solvent and Water Assited Electrical Heating}

Mossa et.al [56] purposed a method of electrical heating using solvent and water for in-situ extraction of bitumen in which the heat is targeted into the formation using downhole electrical heating with a fluid to heat transfer [57]-[59], then the vapor chamber is created for the project of steam-assisted gravity drainage. The project is promising to reduce water surface required to create the steam, and it more advantages over the SAGD project in the side of capital operation cost [60] .

\subsection{Electromagnetic Heating}

Electromagnetic heating is a highly promising EOR method for heavy oil recovery. By using the electromagnetic heating (EM) process method, the volume of heat generated is called the eddy current loss. Eddy current is the induction of an electromagnetic field produced by an AC current that is driven through an inductor cable. The inductor cable is placed in a circle in the reservoir. Reservoir heating using inductor cables is a new technology developed by Siemens, a joint project with Wintershall [61], [62].

EM heating emphasizes the joule effect of eddy currents using AC current, the conduction path in eddy current is connate water in the reservoir. The electric current that is converted to heat through this pathway is caused due to the electrical resistivity in the water formation containing dissolved salt ions. This current distribution depends on the characteristics of the electrical medium in the form of electrical conductivity and permittivity along with the frequency used [61], [63]-[65]. The advantages of the EM method are that the transfer of thermal energy to the reservoir is very effective and can be controlled directly, where it is not limited to depth, heterogeneous formations, and low formation permeability even more lithology of the formation. The use of discontinuous power supply (windmills, solar energy) is feasible which the upper heating temperature limit with current technology is approximately $250^{\circ} \mathrm{C}$ and a small environmental footprint is possible [61].

\subsection{Ultra Sonic Waves}

Ultrasonic is one of the electrical heating for enhanced oil recovery. Ultrasonic has frequencies above human hearing that is around $20 \mathrm{kHz}$. The role of ultrasonic waves is used to move particles in the sample. The technical stimulation of Ultrasonic waves is to support the EOR process and to avoid damage to the production formation including in the promising stimulation technology for new wells to improve oil recovery [66]. Ultrasonic waves will make vibrations around the reservoir increasing capillary strength, adhesion between rocks and liquids which they will facilitate the production and cause of oil coalescence.

\subsection{Radio frequency}

Radio-frequency (RF) technology which is often applied for the cumulative acquisition of heavy oil around the borehole [67], [68]. Literature shows Radio Frequency Heating is more practical than electrical resistive for surface oil sand which RFH is cheaper, quicker and heating is uniform and deeper than ERH, with oil recoveries ranging from 50 to $80 \%$ [58], when the RF process occurs continuously and provides excessive heat around the borehole, and it can damage the integration around the borehole and equipment from the radio frequency [69].

Radio Frequency is electromagnetic radiation from an antenna positioned in a wellbore adjacent to an oil reservoir layer [70]-[72]. Electromagnetic energy will penetrate a considerable distance into the previous oil-carrying layer, and will be absorbed or removed, and converted to thermal energy using forces as low as $5 \mathrm{~kW}$ to as high as $100 \mathrm{~kW}$ [73]. Radio-Frequency equipment consists of an antenna array for heating heavy oil, then various thermal and electrical properties are shown in quadrant four which coordinates the reservoir properties and temperature distributions which are calculated based on the coupling between electromagnetic and field between temperatures [1], [74].

This Radio-frequency method also has the advantage of a rapid heating speed and relatively small heat loss where this will increase the efficiency of oil production and heat can be transmitted 
through the casing and into the reservoir by heat conduction [75], [76]. Particularly, radio frequency can reduce heat loss through the seal rock [77]. Besides it, the disadvantage of this method is the relatively high deployment cost compared to the resistive and inductive electrical heating methods, and the Electrical Heating range is limited, especially when the heat transfer capacity of the reservoir is not good [69], [73].

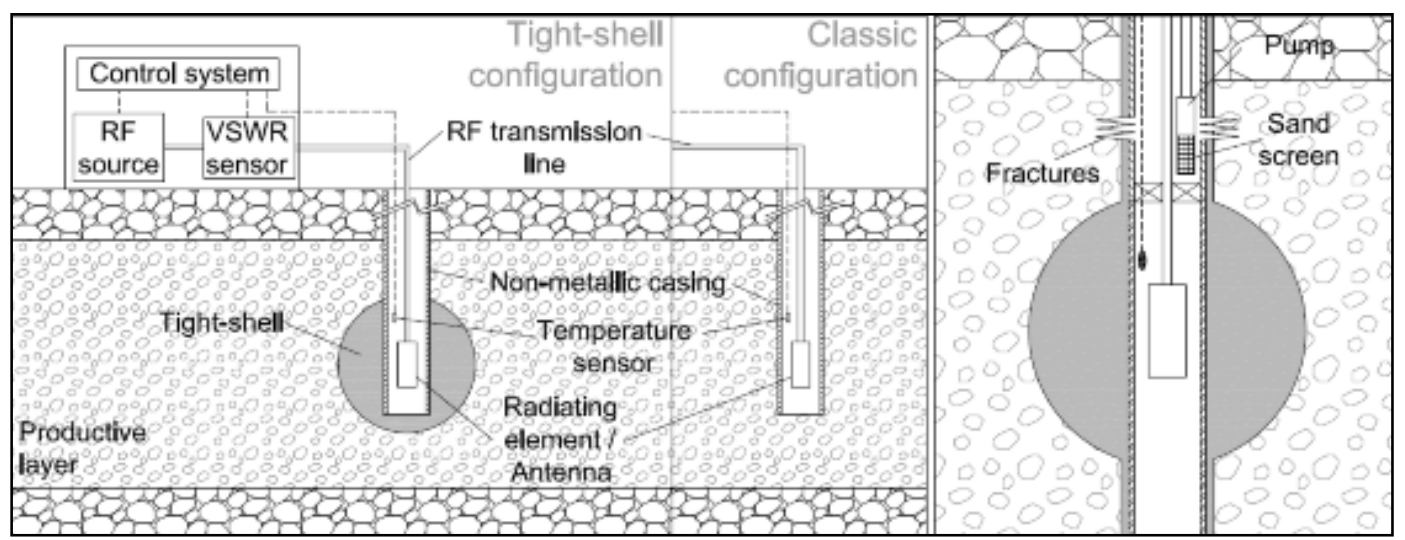

Figure 2. Scheme of the RF radiating well in the tight-shell configuration and in the classic configuration (left) and particular of a possible radiating/producing well completion with tight shell (right)

Reservoir heating rates require high electromagnetic power to be irradiated by downhole antennas which produce very high EM fields in the volume surrounding the antenna [78]. The RF heating process must take into account the distribution of energy through the reservoir and must be designed to achieve an even heating volume. This prevents exposure to components of well completion at extreme temperatures when irradiated with high Electromagnetic power to the reservoir [79].

At this time the RF method is combined with a downhole antenna with an interface structure (called a tight shell) and is realized with radiating wells and reservoirs. A schematic method on figure 3 shows that oil production wells (the settlement scheme, illustrated on the right-hand side of Figure 3, specifically designed to accommodate RF/MW components and allow EM irradiation), High power $\mathrm{RF} / \mathrm{MW}$ (consisting of surface units with high power RF/MW energy sources, downhole transmission lines and downhole antennas), and a tight shell (a round or cylindrical structure that is placed between the oil well and the reservoir realize at the depth of an antenna installation through drilling and finishing operations; the tight shell must be made of low loss dielectric material and impermeable to the reservoir fluid).

According to the frequency of electrical heating, electrical heating is divided into two parameters, which low frequency is used for ohmic and resistive heating is used for microwave heating method:

\subsubsection{Low frequency electric resistive / ohmic}

Low-frequency electric called ohmic or joule heating is a method to heat the reservoir by flowing electrical current through the formation [2], [80], [81]. Ohmic occurs when low-frequency from AC current flows to the reservoir and the electrical heating is converted to heat energy [21]. The main objectivity of the low-frequency electric implementation inside the reservoir is to provide a heating source and to facilitate the oil flow due to the reduction of oil viscosity induced by locally increased temperature. 


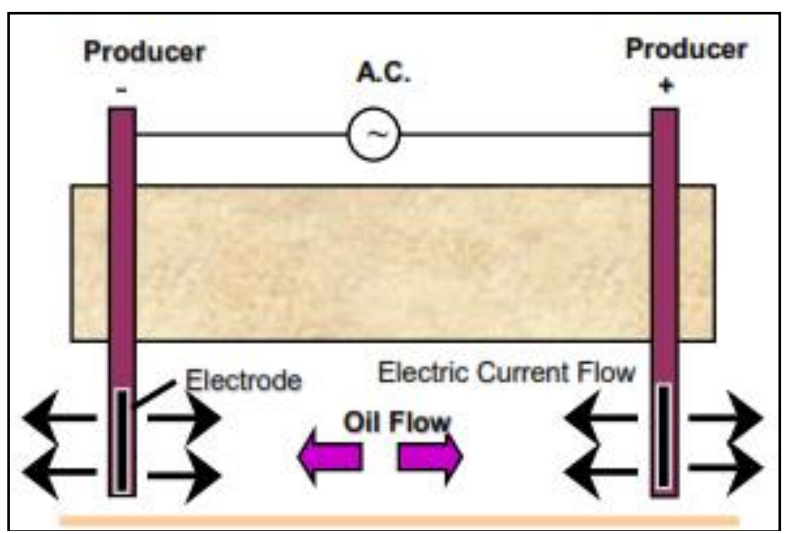

Figure 3. Schematic of low frequency electric resistive [21]

Potential different from the picture above, the electrodes can help the oil flowing due to the current, it also can be applied to the reservoir with salt contents and distribute heat evenly. This method can be applied on various types of reservoirs that have different depth of formation, porosity and permeability, temperature, pressure and thickness [2].

\subsubsection{High frequency microwave heating}

Microwave heating is high-frequency heating where the wave range ranges from $300-300000$ $\mathrm{MHz}$ [82]. Therefore, it is called a microwave due to a short wavelength. Microwave produces more efficient heat at the adsorption in the material but crude oil does not have good adsorption in the microwave. Microwave heating is affected by the design of the microwave source and dielectric properties [83], [84]. The nature of the dielectric depends on the operating frequency, reservoir temperature, etc. Hydrocarbons mixed with sand can absorb large amounts of microwaves, and hydrocarbon can be rapidly heated to temperatures as high as 300-400 C [2], [85].

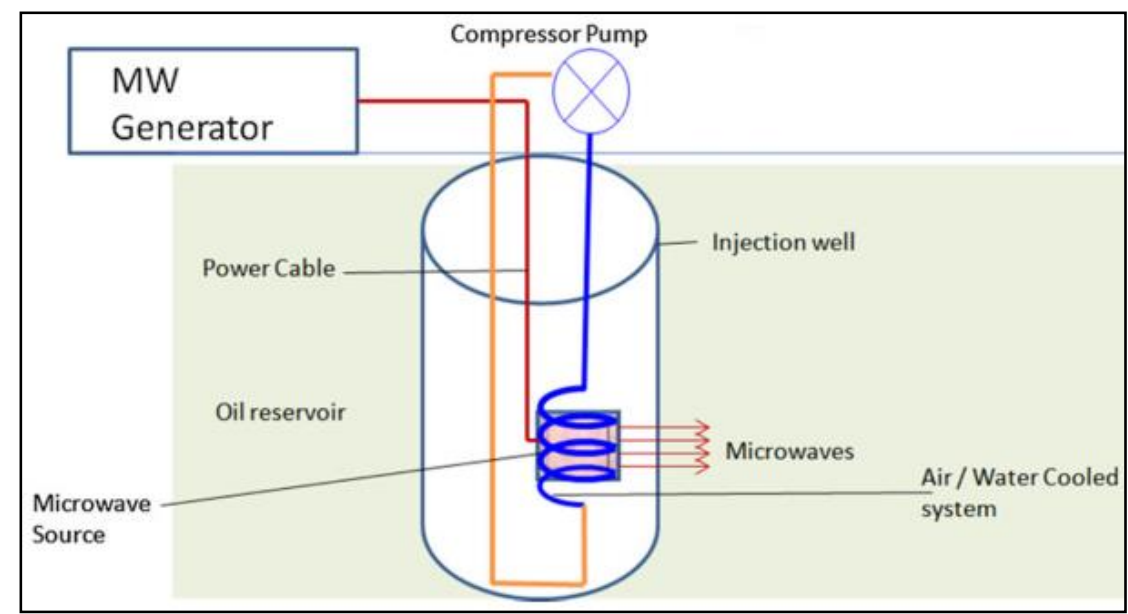

Figure 4. A microwave based EOR setup [2]

Microwave is transmitted through a unit called a waveguide, located on the surface. Waves that move from the waveguide will be emitted from the subsurface antenna to the source of the well [86][89]. The antenna is placed at the water-hydrocarbon interface. The source well is surrounded by production wells [90], [91]. Liquid and steam products are simultaneously pumped from sources and recovery wells. Fluid from the source well is transferred to the storage tank. Steam is condensed into liquid and stored separately. Uncondensed steam will be released, burned, or re-treatment depending on the project location. The fluid pump obtains hydrocarbons from the top of the water face and produces little water. The energy source effectively pulls the hydrocarbon wadding toward the recovery well. The microwave system basically can only recover free products and volatile steam. Laboratory experiments also show that microwave energy will magnify MTBE [92]. 
In other hands, Microwave studies, have shown that when a microwave is added a chemical reaction increases the temperature up to 10-1000 times faster than conventional heating. Recently, microwave irradiation has been used in the petroleum industry, which is applied for bitumen and heavy oil. One of the advantages of the microwave study can be reducing viscosity (more than $96 \%$ ), the reaction time is shorter (less than 60 minutes) which the temperature tends to $150{ }^{\circ} \mathrm{C}[4]$.

Microwave technology has been proven to reduce costs compared to alternative methods such as pumps and maintenance systems by eliminating contamination in source wells without further maintenance [92]. The advantages of microwave irradiation include short processing time, rapid heating, high energy efficiency, and precise control processes. The microwave heating process can be divided into two stages. The electrical energy is input and converted into microwave energy, then converted into effective heat. The energy efficiency of this process is the economic performance index. Experimental studies show that the total energy efficiency of microwave heating can be reached approximately $80 \%$ [4]. 
Table 2. Advantages and Disadvantages of Electrical heating methods

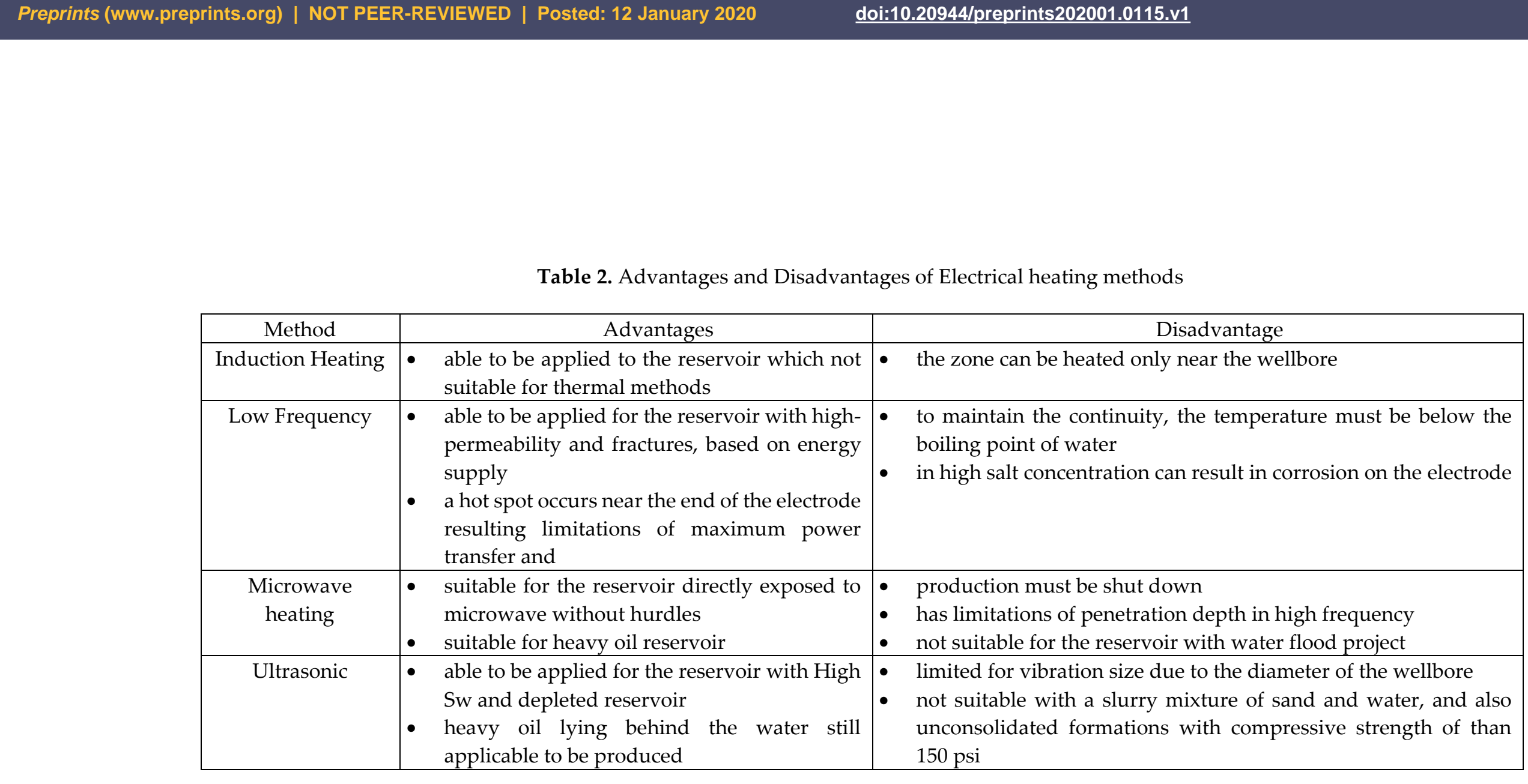

\footnotetext{
$$
\text { . }
$$$$
\text { (1) }
$$

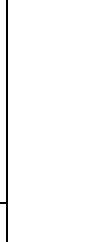

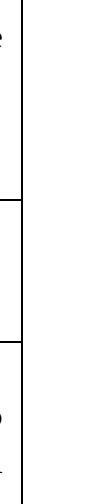




\section{Future of Electrical Heating}

Since the reduced availability of reserves from light oil, heavy oil has become produced commercially. The heavy oil and bitumen reserves are estimated 8-9 trillion barrels worldwide. Technology for producing heavy oil has been developed in many years and has been a task of high importance and complexity which integrated studies approach planning and piloting is a success key of heavy oil projects [93].

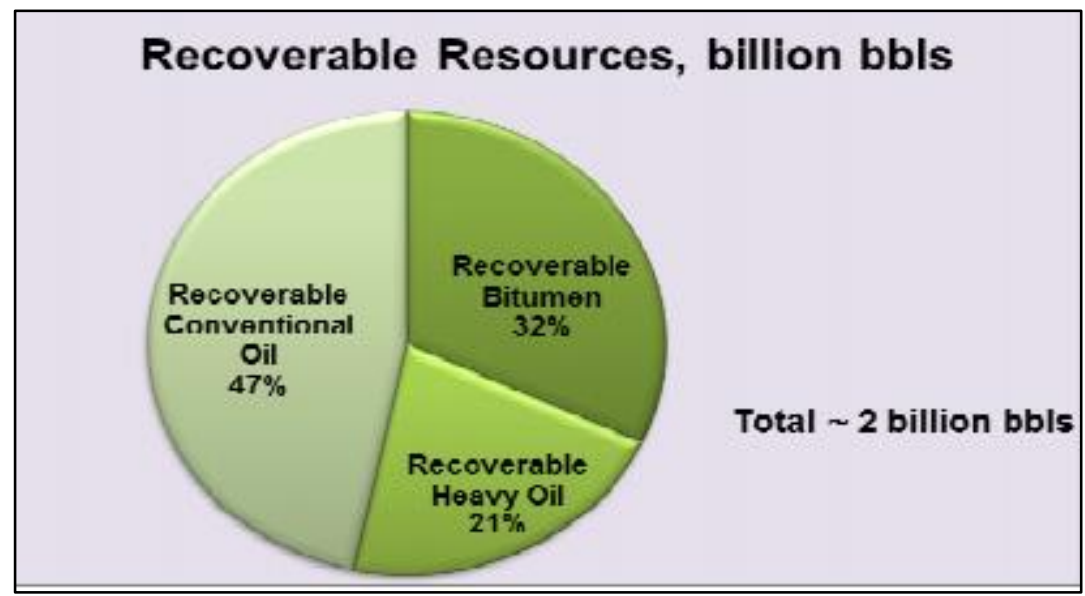

Figure 5. Global recoverable [94]

Electrical heating using mineral isolated is to purpose start-up period from heat source, it can be self-regulating to manage reservoir temperature and to avoid an overheating reservoir. This method doesn't need brine to conduct electricity that polymer and graphite are used instead of brine. Not only electrical heating increases the temperature, but the mineral resistance also increases temperature even more [2]. This method can efficiently avoid a steam breakthrough and be cost less than other conventional methods for heavy oil recovery. In this case, formation damage can be neglected because there is no fluid injected into the reservoir [51].

Artificial intelligence can solve some cases in many ways. AI refers to algorithms that can be taught to some works. AI also plays roles in the oil and gas industries which can be used as a predictive or smart, self-calibrating sensors monitoring operation equipment and forecast operational issues and potential failures [95]. Artificial intelligence and machine learning are a method using the domain of computational intelligence focused on model learning from data to find out the hidden insights and patterns without being explicitly programmed [96]. For example, the artificial neural network (ANN) simulates individual neurons like a biological neural system to purpose made up of a series of interconnected nodes. This method, ANN, draws the pattern recognitions and forecasting in some situations of the complex process [97]. Artificial intelligence can be applied for electrical heating to predict heat quantities required by the reservoir, when electrification increases the number of controllable units as the energy system becomes more complex which simulation data can be input into using algorithms to be taught using machine learning before artificial intelligence is ready for used.

Rassensof reported a new method of electromagnetic using solvent extraction called Enhanced Solvent Extraction Incorporating Electromagnetic Heating Technology (ESEIEH) which has been patented and is currently undergoing tests. this project has been developed in Alberta, Canada. a method of ESEIEH is to combine heating using RF-EM waves and solvents such as propane and butane used in the Canadian-oil sands which commonly is designed for horizontal well. The ESEISEH is developed by three companies, Laricina Energy, Nexen, and Suncor Energy that is running an antenna underground that emits to raise temperature up to $50^{\circ} \mathrm{C}\left(120^{\circ} \mathrm{F}\right)$ [98], [99].

Electrical heating was carried out to advance development to produce heavy oil. Various studies to date are mostly limited to laboratory experiments and numerical models. To meet efficiency energy, producing heating for electricity, is using the sludge from waster material as a component producing 
electricity from biogas. To meet efficiency energy, producing heating from electricity is using the sludge from waster material as a component producing electricity from biogas, but this method showed that is not sustainable for the long term [100]. Smart and sustainable district heating holds great potential to reduce emissions. there many ways to produce electricity by eco-friendly ways.

\section{Conslusion}

Electrical heating is a method of EOR called Electrical-enhanced oil recovery (EEOR) that can be an alternative method for heavy oil than the conventional method. There are three fundamental heat transfers of the electrical heating method into the formation using electric current (heat conduction, heat convection, and radiation heat transfer). The amount of required electric current depends on the rate of production because, when the hot water is producing, the colder fluid will be flowing from the reservoir to the well. The excessive energy will give uncontrolled temperature and damages formation where the mode of electrical heating depends on the frequency of the electric current and components such as power conditioning unit, power delivery system, electrode assembly, and ground return systems. The past and current developments have been carried out to fill up the gap of electrical heating projects. The future prospects must meet energy efficiency, and the excessive heat will damage formation that must be tackled in the future prospect. the works adopt several electrical heating projects and applications in the world where the works give a brief future project of electrical heating.

\section{Abbreviations}

The following abbreviations are used for this manuscript :

AC Alternative current

AI Artificial intelligence

ANN Artificial neural network

API American petroleum institute

CSS Cyclic stem stimulation

DC Direct current

EEOR Electrical enhanced oil recovery

EM Electromagnetic

EOR Enhanced oil recovery

ERH Electrical resistive heating

ESEIEH Enhanced solvent extraction incoporating electromagnetic heating technology

GEHGD Gas and electrical heating gravity drainage

MMT Million metric tonnes

MW Mircowave

OOIP Original oil in place

KW Kilowatt

RF Radio frequency

RF-EM Radio frequency-electromagnetic

RFH Radio frequency heating

SAGD Steam assited gravity drainage 
Author Contributions: Conceptualization, T.E and M.K.A.; methodology, M.Y.H. and S.R ; formal analysis, F.A. and R.W.; resources, L.P. and R.S; writing-original draft preparation, M.Y. and R.S..; writing-review and editing, M.Y. and F.A; project administration, F.P.; funding acquisition, A.S. and M.F.A.

Funding: Please add: This research received no external funding

Acknowledgments: This reaserch has been partially Supported by Universitas Islam Riau

Conflicts of Interest: The authors declare no conflicts of interest or state .

\section{References}

[1] M. Bientinesi et al., "Journal of Petroleum Science and Engineering A radiofrequency / microwave heating method for thermal heavy oil recovery based on a novel tight-shell conceptual design," J. Pet. Sci. Eng., pp. 1-13, 2013.

[2] M. M. Rehman and M. Meribout, "Conventional versus electrical enhanced oil recovery: A review," J. Pet. Explor. Prod. Technol., vol. 2, no. 4, pp. 169-179, 2012.

[3] M. R. Ado, M. Greaves, and S. P. Rigby, "Effect of pre-ignition heating cycle method, air injection flux, and reservoir viscosity on the THAI heavy oil recovery process," J. Pet. Sci. Eng., vol. 166, pp. 94-103, 2018.

[4] M. Mozafari and Z. Nasri, "Operational conditions effects on Iranian heavy oil upgrading using microwave irradiation," J. Pet. Sci. Eng., vol. 151, pp. 40-48, 2017.

[5] M. Zhu, H. Zhong, Y. Li, C. Zeng, and Y. Gao, "Research on viscosity-reduction technology by electric heating and blending light oil in ultra-deep heavy oil wells," J. Pet. Explor. Prod. Technol., vol. 5, no. 3, pp. 233-239, 2015.

[6] J. Greff and T. Babadagli, "Use of nano-metal particles as catalyst under electromagnetic heating for insitu heavy oil recovery," J. Pet. Sci. Eng., vol. 112, pp. 258-265, 2013.

[7] R. M. Madhavan and D. D. Mamora, “Experimental investigation of caustic steam injection for heavy oils," in SPE Improved Oil Recovery Symposium, 2010.

[8] J. G. Speight, Enhanced recovery methods for heavy oil and tar sands. 2013.

[9] D. Hill, “Application of Electrokinetics for Enhanced Oil Recovery," Electrokinet. Pet. Environ. Eng., pp. 103-155, 2014.

[10] A. Bera and T. Babadagli, "Status of electromagnetic heating for enhanced heavy oil / bitumen recovery and future prospects : A review," Appl. Energy, vol. 151, pp. 206-226, 2015.

[11] A. Sadeghi, H. Hassanzadeh, and T. G. Harding, "International Journal of Heat and Mass Transfer A comparative study of oil sands preheating using electromagnetic waves, electrical heaters and steam circulation," Int. J. Heat Mass Transf., vol. 111, pp. 908-916, 2017.

[12] K. Vinsome, B. C. W. McGee, F. E. Vermeulen, and F. S. Chute, “Electrical heating," J. Can. Pet. Technol., vol. 33, no. 04, 1994.

[13] H. Hassanzadeh and T. Harding, "Analysis of conductive heat transfer during in-situ electrical heating of oil sands," Fuel, vol. 178, pp. 290-299, 2016.

[14] T. N. Nasr, D. H. S. Law, H. Golbeck, and G. Korpany, “Counter-current Aspect of the SAGD Process," J. Can. Pet. Technol., vol. 39, no. 01, p. 7, 2000.

[15] Z. X. Yao, J. X. Li, K. Wang, Y. N. Song, and X. Li, “Experimental and numerical study on direct electrical heating for plug removal of subsea waxy crude pipelines," Int. J. Heat Mass Transf., vol. 143, p. 118489, 2019.

[16] B. C. W. McGee, F. E. Vermeulen, and L. Yu, “Field test of electrical heating with horizontal and vertical wells," J. Can. Pet. Technol., vol. 38, no. 03, 1999. 
[17] W. Yongbin et al., "Numerical Simulation of Electrical-Heating Assisted SAGD in Heterogeneous Heavy Oil Reservoirs," in SPE Reservoir Characterisation and Simulation Conference and Exhibition, 2017.

[18] J. Y. Yuan, H. Huang, R. Mintz, X. Wang, C. Jossy, and C. Tunney, “Wet electric heating for starting up SAGD/VAPEX," in Canadian International Petroleum Conference, 2004.

[19] B. C. W. McGee, F. E. Vermeulen, and C. L. Yu, “Electrical Heating With Horizontal And Vertical Wells,” in Annual Technical Meeting, 1996.

[20] S. K. Das, "Electro magnetic heating in viscous oil reservoir," in International Thermal Operations and Heavy Oil Symposium, 2008.

[21] A. Sahni, M. Kumar, and R. B. Knapp, "Electromagnetic heating methods for heavy oil reservoirs," SPE/AAPG West. Reg. Meet., pp. 257-266, 2000.

[22] R. G. Santos, W. Loh, A. C. Bannwart, and O. V Trevisan, “An overview of heavy oil properties and its recovery and transportation methods," Brazilian J. Chem. Eng., vol. 31, no. 3, pp. 571-590, 2014.

[23] G. C. Thakur, "Heavy Oil Reservoir Management," in Latin American and Caribbean Petroleum Engineering Conference, 1997.

[24] C. D. Wehunt, N. E. Burke, S. G. Noonan, and T. R. Bard, "Technical challenges for offshore heavy oil field developments," in Offshore Technology Conference, 2003.

[25] S. K. Das, “Application of thermal processes in heavy oil carbonate reservoirs," SPE Middle East Oil and Gas Show and Conference. Society of Petroleum Engineers, Manama, Bahrain, p. 9, 2007.

[26] B. Hascakir, T. Babadagli, and S. Akin, “Experimental and numerical modeling of heavy-oil recovery by electrical heating," in International Thermal Operations and Heavy Oil Symposium, 2008.

[27] T. N. Nasr and O. R. Ayodele, “Thermal techniques for the recovery of heavy oil and bitumen," in SPE international improved oil recovery conference in Asia Pacific, 2005.

[28] Y. Bao, J. Wang, and I. D. Gates, "Steam injection gravity drainage as a follow-up process for cyclic steam stimulation," J. Pet. Sci. Eng., vol. 153, pp. 268-282, 2017.

[29] J. P. Batycky, R. P. Leaute, and B. A. Dawe, “A Mechanistic Model of Cyclic Steam Stimulation," International Thermal Operations and Heavy Oil Symposium. Society of Petroleum Engineers, Bakersfield, California, p. 14, 1997.

[30] E. A. P. Putra, Y. A. Rachman, T. Firmanto, R. Arsyadanie, and G. Hafizh, “Case Study: Cyclic Steam Stimulation in Sihapas Formation," in SPE Asia Pacific Oil and Gas Conference and Exhibition, 2011.

[31] E. Ghoodjani, R. Kharrat, M. Vossoughi, and S. H. Bolouri, “A review on thermal enhanced heavy oil recovery from fractured carbonate reservoirs," in SPE heavy oil conference Canada, 2012.

[32] D. N. Dietz, "Review of thermal recovery methods," in Fall Meeting of the Society of Petroleum Engineers of AIME, 1975.

[33] K. D. Vincent, C. J. MacKinnon, and C. T. S. Palmgren, “Developing SAGD Operating Strategy using a Coupled Wellbore Thermal Reservoir Simulator," SPE International Thermal Operations and Heavy Oil Symposium and Western Regional Meeting. Society of Petroleum Engineers, Bakersfield, California, p. 8, 2004.

[34] V. Alvarado and E. Manrique, “Enhanced oil recovery: an update review," Energies, vol. 3, no. 9, pp. 1529-1575, 2010.

[35] G. Giacchetta, M. Leporini, and B. Marchetti, “Economic and environmental analysis of a Steam Assisted Gravity Drainage (SAGD) facility for oil recovery from Canadian oil sands," Appl. Energy, vol. 142, pp. $1-9,2015$.

[36] Y. Wang, X. Wang, Y. Xing, J. Xue, and D. Wang, “Three-dimensional numerical simulation of enhancing 
shale gas desorption by electrical heating with horizontal wells," J. Nat. Gas Sci. Eng., vol. 38, pp. 94-106, 2017.

[37] C. Xi et al., “Dual-Horizontal Wells SAGD Start-Up Technology: From Conventional Steam Circulation to Rapid and Uniform Electric Heating Technology," SPE Symposium: Production Enhancement and Cost Optimisation. Society of Petroleum Engineers, Kuala Lumpur, Malaysia, p. 9, 2017.

[38] L. I. U. Xiaoxiong, Y. JIANG, W. U. Yongbin, and W. Jialu, “A mathematical model and relevant index prediction for constant-temperature electric heating of dual-horizontal-well SAGD start-up," Pet. Explor. Dev., vol. 45, no. 5, pp. 895-902, 2018.

[39] D. Ji, S. Yang, H. Zhong, M. Dong, Z. Chen, and L. Zhong, “Re-Examination of Fingering in SAGD and ES-SAGD," in SPE Canada Heavy Oil Technical Conference, 2016.

[40] M. Carlson, “SAGD and Geomechanics," J. Can. Pet. Technol., vol. 42, no. 06, 2003.

[41] A. Sood, "Convective SAGD Process," in SPE Canada Heavy Oil Technical Conference, 2016.

[42] D. L. Stinson, H. C. Carpenter, and J. M. Cegielski Jr, “Power recovery from in-situ combustion exhaust gases," J. Pet. Technol., vol. 28, no. 06, pp. 645-650, 1976.

[43] S. M. Ali, “Steam Injection Theories-A Unified Approach," in SPE California Regional Meeting, 1982.

[44] M. O. Onyekonwu, K. Pande, H. J. Ramey Jr, and W. E. Brigham, “Experimental and simulation studies of laboratory in-situ combustion recovery," in SPE California Regional Meeting, 1986.

[45] S. Melcon, “Oil recovery by in situ combustion.” Google Patents, 12-Jan-1965.

[46] A. Doraiah, S. Ray, and P. Gupta, "In-situ combustion technique to enhance heavy oil recovery at Mehsana," ONGC-a success story SPE, vol. 105248, 2007.

[47] I. D. Gates and S. R. Larter, “Energy efficiency and emissions intensity of SAGD,” Fuel, vol. 115, pp. 706$713,2014$.

[48] C. Sandberg, K. Thomas, and A. Hale, "Advances in electrical heating technology for heavy oil production," in SPE Heavy Oil Conference-Canada, 2014.

[49] V. O. Zyrin and B. U. Vasiliev, "Electrothermal complex with downhole electrical heating generators for enhanced heavy oil recovery," Int. J. Appl. Eng. Res., vol. 11, no. 3, pp. 1859-1866, 2016.

[50] B. C. W. McGee and F. E. Vermeulen, "The mechanisms of electrical heating for the recovery of bitumen from oil sands," J. Can. Pet. Technol., vol. 46, no. 01, 2007.

[51] E. R. Rangel-German, J. Schembre, C. Sandberg, and A. R. Kovscek, “Electrical-heating-assisted recovery for heavy oil," J. Pet. Sci. Eng., vol. 45, no. 3-4, pp. 213-231, 2004.

[52] Z. Zhu, F. Zeng, G. Zhao, and P. Laforge, “Evaluation of the hybrid process of electrical resistive heating and solvent injection through numerical simulations," Fuel, vol. 105, pp. 119-127, 2013.

[53] L. Zhong, D. Yu, H. Yang, Y. Sun, G. Wang, and J. Zheng, “Feasibility Study on Produce Heavy Oil by Gas and Electrical Heating Assisted Gravity Drainage," in Offshore Technology Conference, 2011.

[54] M. Koolman, N. Huber, D. Diehl, and B. Wacker, "Electromagnetic heating method to improve steam assisted gravity drainage," in International Thermal Operations and Heavy Oil Symposium, 2008.

[55] L. Hu, H. A. Li, T. Babadagli, and M. Ahmadloo, "Experimental investigation of combined electromagnetic heating and solvent-assisted gravity drainage for heavy oil recovery," J. Pet. Sci. Eng., vol. 154, pp. 589-601, 2017.

[56] M. R. Faradonbeh, H. Hassanzadeh, and T. Harding, “Numerical simulations of bitumen recovery using solvent and water assisted electrical heating," Fuel, vol. 186, pp. 68-81, 2016.

[57] W. Guo et al., "Experimental investigation on performance of downhole electric heaters with continuous helical baffles used in oil shale in-situ pyrolysis," Appl. Therm. Eng., vol. 147, pp. 1024-1035, 2019. 
[58] T. Ramcharan and R. Hosein, "Radio Frequency Heating combined with Solvent Extraction-A method for oil recovery from surface oil sands," J. Pet. Sci. Eng., vol. 179, pp. 328-336, 2019.

[59] L. Andarcia, J. M. Bermudez, Y. Reyes, H. Caycedo, and A. F. Suarez, “Potential of Steam Solvent Hybrid Processes in Llanos Basin, Colombia," SPE Heavy and Extra Heavy Oil Conference: Latin America. Society of Petroleum Engineers, Medellín, Colombia, p. 16, 2014.

[60] A. Seeam, D. Laurenson, and A. Usmani, "Evaluating the potential of simulation assisted energy management systems: A case for electrical heating optimisation," Energy Build., vol. 174, pp. 579-586, 2018.

[61] M. Rafiee, A. Behr, E. Lessner, D. Diehl, B. Trautmann, and A. Koch, “Electromagnetic heating for heavy oil production: Case study of a field applicability," Soc. Pet. Eng. - SPE Russ. Pet. Technol. Conf., 2015.

[62] J. Taheri-Shakib, A. Shekarifard, and H. Naderi, "Experimental investigation of comparing electromagnetic and conventional heating effects on the unconventional oil (heavy oil) properties: Based on heating time and upgrading," Fuel, vol. 228, pp. 243-253, 2018.

[63] U. Roland, F. Holzer, and F. Kopinke, "Combining different frequencies for electrical heating of saturated and unsaturated soil zones," Chem. Eng. Technol., vol. 34, no. 10, pp. 1645-1651, 2011.

[64] J.-H. Chen, D. T. Georgi, and H.-H. Liu, “Electromagnetic thermal stimulation of shale reservoirs for petroleum production," J. Nat. Gas Sci. Eng., vol. 59, pp. 183-192, 2018.

[65] A. Sadeghi, H. Hassanzadeh, and T. G. Harding, "Modeling of desiccated zone development during electromagnetic heating of oil sands," J. Pet. Sci. Eng., vol. 154, pp. 163-171, 2017.

[66] H. K. Abdulfatah, "Application of Ultrasonic Waves in Enhancing Oil Recovery in Secondary Recovery Phase," in SPE Annual Technical Conference and Exhibition, 2018.

[67] M. Bientinesi et al., "A radiofrequency/microwave heating method for thermal heavy oil recovery based on a novel tight-shell conceptual design," J. Pet. Sci. Eng., vol. 107, pp. 18-30, 2013.

[68] I. Bogdanov, S. Cambon, and C. Prinet, "Analysis of Heavy Oil Production by Radio-Frequency Heating," SPE International Heavy Oil Conference and Exhibition. Society of Petroleum Engineers, Mangaf, Kuwait, p. 13, 2014.

[69] Z. Wang, D. Gao, and J. Fang, "Numerical simulation of RF heating heavy oil reservoir based on the coupling between electromagnetic and temperature field," Fuel, vol. 220, no. January, pp. 14-24, 2018.

[70] A. Bera and T. Babadagli, "Effect of native and injected nano-particles on the efficiency of heavy oil recovery by radio frequency electromagnetic heating," J. Pet. Sci. Eng., vol. 153, pp. 244-256, 2017.

[71] A. Davletbaev, L. Kovaleva, T. Babadagli, and R. Minnigalimov, "Heavy oil and bitumen recovery using radiofrequency electromagnetic irradiation and electrical heating: Theoretical analysis and field scale observations," in Canadian Unconventional Resources and International Petroleum Conference, 2010.

[72] A. Saeedfar, D. Lawton, and K. Osadetz, “Directional RF Heating for Heavy Oil Recovery Using Antenna Array Beam-Forming," SPE Canada Heavy Oil Technical Conference. Society of Petroleum Engineers, Calgary, Alberta, Canada, p. 34, 2016.

[73] D. Oloumi and K. Rambabu, "Microwave heating of heavy oil reservoirs: A critical analysis," Microw. Opt. Technol. Lett., vol. 58, no. 4, pp. 809-813, 2016.

[74] A. Davletbaev, L. Kovaleva, and T. Babadagli, "Mathematical modeling and field application of heavy oil recovery by radio-frequency electromagnetic stimulation," J. Pet. Sci. Eng., vol. 78, no. 3-4, pp. 646$653,2011$.

[75] Z. Wang, D. Gao, B. Diao, L. Tan, W. Zhang, and K. Liu, “Comparative performance of electric heater vs. RF heating for heavy oil recovery," Appl. Therm. Eng., vol. 160, no. July, p. 114105, 2019. 
[76] R. S. Kasevich, S. L. Price, and A. Albertson, "Numerical Modeling of Radio Frequency Heating Process for Enhanced Oil Production," SPE Western Regional Meeting. Society of Petroleum Engineers, Long Beach, California, p. 5, 1997.

[77] A. Cerutti et al., “A New Technique for Heavy Oil Recovery Based on Electromagnetic Heating: System Design and Numerical Modelling," Chem. Eng. Trans., vol. 32, p. 1255, Jan. 2013.

[78] S. Marfissi, F. Campos, C. Osuna, and J. Brown, “EVALUATION OF DOWNHOLE ELECTRICAL HEATING IN HEAVY OIL OF THE ORINOCO BELT, VENEZUELA.," 2009.

[79] B. Hascakir, T. Babadagli, and S. Akin, "Field-scale analysis of heavy-oil recovery by electrical heating," SPE Reserv. Eval. Eng., vol. 13, no. 1, p. PP-131, 2010.

[80] M. Seidi Damyeh, M. Niakousari, M. T. Golmakani, and M. J. Saharkhiz, "Microwave and ohmic heating impact on the in situ hydrodistillation and selective extraction of Satureja macrosiphonia essential oil," J. Food Process. Preserv., vol. 40, no. 4, pp. 647-656, 2016.

[81] E. J. Martin, K. G. Mumford, B. H. Kueper, and G. A. Siemens, “Gas formation in sand and clay during electrical resistance heating," Int. J. Heat Mass Transf., vol. 110, pp. 855-862, 2017.

[82] L. Hanyong, C. Kexin, J. Ling, W. Leilei, and Y. Bo, “Experimental study on the viscosity reduction of heavy oil with nano-catalyst by microwave heating under low reaction temperature," J. Pet. Sci. Eng., vol. 170, pp. 374-382, 2018.

[83] H. Wang, R. Rezaee, A. Saeedi, and M. Josh, “Numerical modelling of microwave heating treatment for tight gas sand reservoirs," J. Pet. Sci. Eng., vol. 152, pp. 495-504, 2017.

[84] J. Zhu, Z. Yang, X. Li, S. Qi, Q. Fang, and Y. Ding, “The experimental study of microwave heating on the microstructure of oil shale samples," Energy Sci. Eng., vol. 7, no. 3, pp. 809-820, 2019.

[85] J. Taheri-Shakib, A. Shekarifard, and H. Naderi, “The experimental investigation of effect of microwave and ultrasonic waves on the key characteristics of heavy crude oil," J. Anal. Appl. Pyrolysis, vol. 128, pp. 92-101, 2017.

[86] N. Bjorndalen and M. R. Islam, "The effect of microwave and ultrasonic irradiation on crude oil during production with a horizontal well," J. Pet. Sci. Eng., vol. 43, no. 3-4, pp. 139-150, 2004.

[87] Z. Nasri and M. Mozafari, "Multivariable statistical analysis and optimization of Iranian heavy crude oil upgrading using microwave technology by response surface methodology (RSM)," J. Pet. Sci. Eng., vol. 161, pp. 427-444, 2018.

[88] J. Taheri-Shakib, A. Shekarifard, and H. Naderi, "Experimental investigation of the asphaltene deposition in porous media: accounting for the microwave and ultrasonic effects," J. Pet. Sci. Eng., vol. 163, pp. 453-462, 2018.

[89] A. K. A. Dandjouma, C. Tchiégang, C. Kapseu, J. Fanni, and M. Parmentier, “Changes in Canarium schweinfurthii Engl. oil quality during microwave heating," Eur. J. lipid Sci. Technol., vol. 108, no. 5, pp. 429-433, 2006.

[90] J. Taheri-Shakib, A. Shekarifard, and H. Naderi, “The experimental study of effect of microwave heating time on the heavy oil properties: Prospects for heavy oil upgrading," J. Anal. Appl. Pyrolysis, vol. 128, pp. 176-186, 2017.

[91] B. Demiral, S. Akin, C. Acar, and B. Hascakir, "Microwave Assisted Gravity Drainage of Heavy Oils," International Petroleum Technology Conference. International Petroleum Technology Conference, Kuala Lumpur, Malaysia, p. 9, 2008.

[92] R. P. Ferri and M. T. Uthe, "Hydrocarbon remediation using microwaves," in SPE/EPA/DOE Exploration and Production Environmental Conference, 2001. 
[93] M. S. Rana, V. Sámano, J. Ancheyta, and J. A. I. Diaz, “A review of recent advances on process technologies for upgrading of heavy oils and residua," Fuel, vol. 86, no. 9, pp. 1216-1231, 2007.

[94] E. Isaacs, "Advances in Extra Heavy Oil Development Technologies (Isaacs)," in 20th World Petroleum Congress, 2011.

[95] C. Kandziora, "Applying Artificial Intelligence to Optimize Oil and Gas Production," in Offshore Technology Conference, 2019.

[96] S. Basfar, S. O. Baarimah, S. Elkatany, W. AL-Ameri, K. Zidan, and A. AL-dogail, “Using Artificial Intelligence to Predict IPR for Vertical Oil Well in Solution Gas Derive Reservoirs: A New Approach," in SPE Kingdom of Saudi Arabia Annual Technical Symposium and Exhibition, 2018.

[97] A. Olawoyin and Y. Chen, "Predicting the Future with Artificial Neural Network," Procedia Comput. Sci., vol. 140, pp. 383-392, 2018.

[98] T. Abraham, A. Afacan, and T. Thundat, "Electrical Heating Strategies for Oil Sands Based on Their Dynamic Electrical Behavior."

[99] H. Hassanzadeh, M. Rabiei Faradonbeh, and T. Harding, "Numerical simulation of solvent and water assisted electrical heating of oil sands including aquathermolysis and thermal cracking reactions," AIChE J., vol. 63, no. 9, pp. 4243-4258, 2017.

[100] A. B. Chhetri and M. R. Islam, "A critical review of electromagnetic heating for enhanced oil recovery," Pet. Sci. Technol., vol. 26, no. 14, pp. 1619-1631, 2008. 